\title{
Features of Identification Elements Deployed along Highways: Example of Ukraine and India
}

\author{
Ophylia Vinodhini ${ }^{1,2}$, Tetyana Lytvynenko ${ }^{3}$, Iryna Tkachenko ${ }^{3}$, Lina Hasenko ${ }^{3 *}$ \\ 1 Department of Architecture, National Institute of Technology, Tiruchirappalli, Tamil Nadu, 620015, India \\ 2 C.A.R.E. School of Architecture, Thayanur, Tiruchirappalli, Tamil Nadu, 620009, India \\ ${ }^{3}$ Department of Roads, Geodesy, Land Management and Rural Buildings Institute of Architecture and Construction, \\ Poltava National Technical Yuri Kondratyuk University, Pershotravnevyi Avenue, 24, Poltava, 36011, Ukraine \\ * Corresponding author, e-mail: lin02011@meta.ua
}

Received: 04 July 2019, Accepted: 08 July 2019, Published online: 15 October 2019

\begin{abstract}
As a result of literature analysis the authors identified the main directions of the road improvement problem study and determined that further research needs the identification elements, which can improve the visual and functional nature of the road. Among the elements of road improvement is distinguished a separate broad group - identification elements, which includes natural objects, historical and cultural monuments and recreational areas. Are revealed the factors influence on the road environment visual perception and the main properties of the road space perception. The authors' studies made it possible to formulate the main requirements for the road space and to propose the principles of calculating the distances between the points of stop along the highways.
\end{abstract}

Keywords

identification elements, road environment, visual perception, traffic conditions

\section{Introduction}

Ukraine and India have plenty of picturesque places, amazing nature, magnificent architecture and ancient historical sites. Each city of countries is beautiful and unique in its own way. It is not always possible for travelers to drive to the city they travel and get acquainted with it, but passing it driver and passengers should feel the peculiarity and specificity of the region, penetrate into its historical heritage. Therefore, it is important when designing the road to consider the issue of ensuring identification elements, which will bring aesthetic satisfaction to the participants of the movement.

Often road sections have a boring landscape, no interesting elements and visual features that is they are not well equipped with elements of improvement, including identification elements. This causes the sensory famine of subjects of motion, the perceptual system of which becomes insensitive, which can lead to an emergency. At the same time the rest of the roads are over-saturated with individual elements of improvement, the placement of which is architecturally disordered. As a result there is an information overload and a driver's psychological stress, which can also adversely affect the safety of the journey and the impression of the trip.
The architecture of highways should focus on two goals: creating conditions for the safety and convenience of traffic; providing along the whole road a single, integrated architectural ensemble against the background of a roadside landscape. Any object of architecture, including on the road, must perform two functions: ideological, artistic and utilitarian-practical.

Over the past decades, the network of roads in the world increased by about 8 times (Kobernik and Kovalenko, 2017). At the same time, the problem of accidents on motor vehicles has become especially acute due to the mismatch of existing road and transport infrastructure in some countries with modern requirements.

The positive dynamics of the development of automobile tourism and the growing interest of domestic and foreign travelers in it, the expansion of international recreational flows and increasing mobility of the population need to find and improve the methods of integrated placement and assessment of objects in the roadside space, as well as identification of its cognitive and recreational potential.

So the purpose of this work - on the basis of historical and literary sources of information review, as well as 
on-the-ground inspections, to classify identification elements, to identify the main properties of road space and their impact on the deployment of identification elements along the highways.

\section{Historical review of the development of road improvement}

The development of humanity is inextricably linked with the development of transport communications. The first signs of the path were separate lying stones, relief changes, and high trees. In ancient Egyptians there was a special hieroglyph for the word "road" - "iat" (Fig. 1).

A special development of road improvement was taken in Ancient India during the Mauriy era (325-185 years BC.). During the reign of King Ashoka, ancient Indian roads were planted with banyan trees and mango groves, "to give a shadow to man and animals." Stone pillars were installed along roads with texts of Buddhist exhortations (Fig. 2).

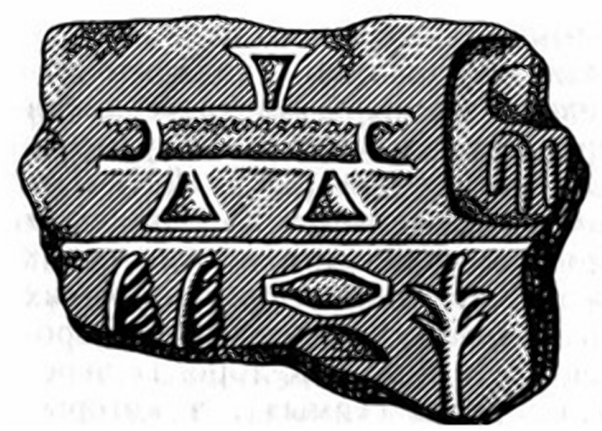

Fig. 1 Egyptian hieroglyph, denoting the word "road"

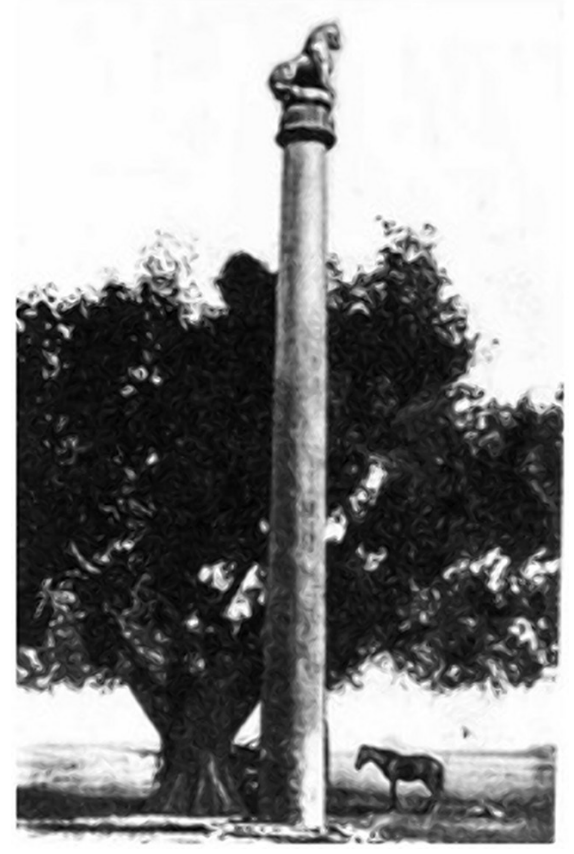

Fig. 2 Roadside pillar in ancient India
The load bearing stones as shown in Fig. 3 (called sumaithaanghikal in Tamil language) are a mandatory element in the entrance of every village. Sumai means load, thaanghi means to bear and kal means stone. These were functional elements to help pilgrims and travelers to keep their bags on the stone and rest awhile.

In VI - VIII centuries nomadic tribes of Polovtsy, the Scythians in the southern steppes of Ukraine installed the famous "stone women" mainly along the routes of communication (Fig. 4).

Middle Ages were a time of widespread Buddhist religion in Southeast Asia and the Far East. Religious and ritual ceremonies connected with the roads have generated here a large number of roadside monuments. Buddhist altars and images of the Buddha were set alongside roads in China, Japan and other countries of Southeast Asia. Small pagodas with a small Buddha figure appear everywhere alongside the land routes. Several palaces, forts, and resting places are built along the frequented and

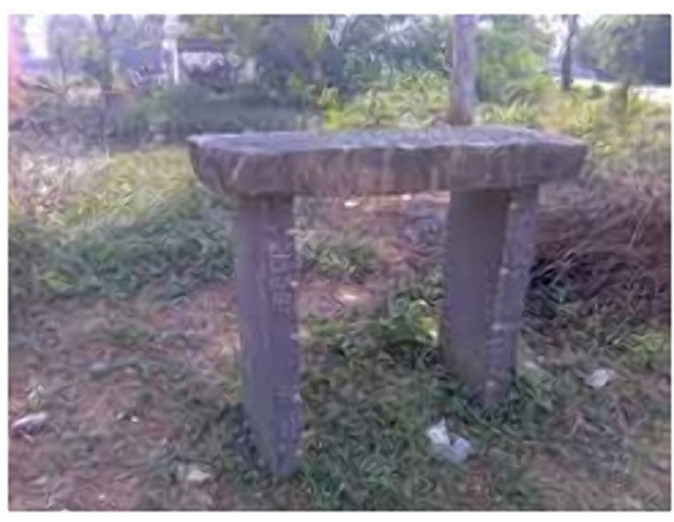

Fig. 3 Load bearing and resting stone. Sumaithaanghi Kal in Tamil language

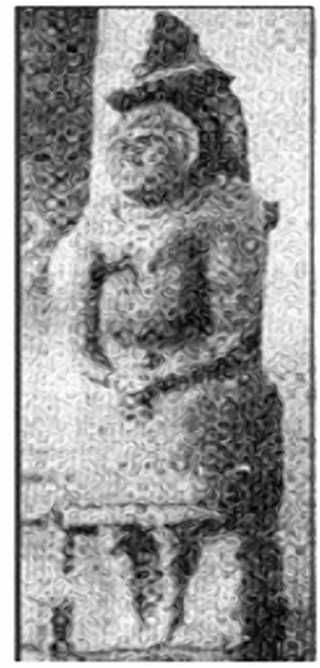

Fig. 4 Roadside sculpture "Polovtsian woman" 
historic travel routes. In India, some of these were built by $1000 \mathrm{AD}$, and now exist in maintained conditions or as ruins (Fig. 5). View of these structures is often desired by the travelers to orient themselves along travel. Long before that important processes took place in the Western Hemisphere. In XV-XVI centuries the Inca Empire in South America built a network of stone paths, which is compared with the network of roads in Ancient Rome. An interesting feature of the roads was the installation of special stone walls in height to the human belt, which kept the road from the drift of sand. On the roads of the Incas there were also bridges (usually hanging or pontoon), tunnels and high stone embankments. The roads were planted with trees that received moisture from special ditches laid along the road. In the towns the road sometimes fenced by a stone wall with decorative painting.

North American states that are not inherited from the Indian road network, started to build the roads from the XVIII century. It is clear that the principles of road improvement, which are used here, are taken from the European continent. Similarly to the European countries are organized postal stations, road signs, road landscaping. However, it is in the United States began major changes in road construction and improvement of the twentieth century, which called "motor century". Chronicle testimonies telling about the military campaigns of the princes of Kievan Rus, allow us to restore the picture of the routes of this period. The roads were not specifically supported, however, in wetlands and small rivers they were arranged at the crossroads of the hailstones and small bridges. Road and border road signs were stones depicting crosses and inscriptions. A noticeable revival of road construction in Europe begins with the XVIII century. The traditional part of the roadside landscape in Europe is the memorials such as small temples, chapels and roadside crosses (Tkachenko, 2013).

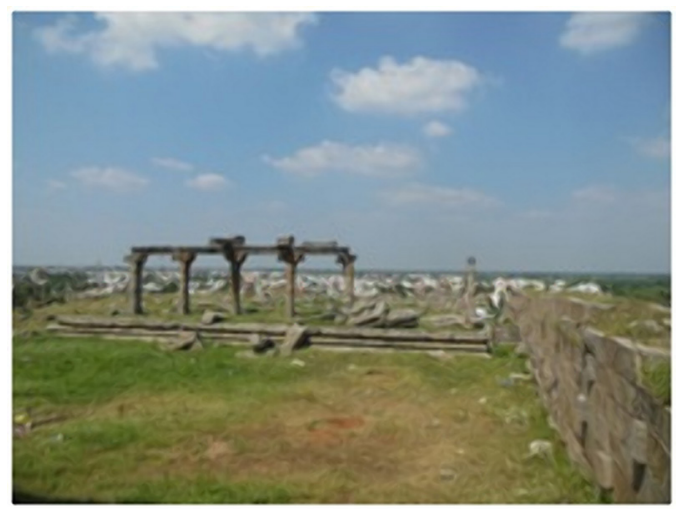

Fig. 5 View of a thousand-year-old ruins from an highway in Tamil Nadu, India

\section{Literature review}

The place identification is an important area of research in various fields of science (Florek, 2010; Morgan, 2010; Scannell and Gifford, 2010). These planning theories are relevant for spaces along highways, because here every element affects the full perception of the place. Petersen et al. (2002) study the problems of roadside space and technology to reduce their impact in developing countries. In the works Nagendraand Gopal (2010), Boarnet (2014) and Vinodhini and Sundaram (2015), considered roadside spaces in the cities of India and the United States. In the works Tkachenko (2013), and Lytvynenko et al. (2017), roadside spaces of cities in Ukraine and other countries of the world are considered.

A new regulatory document has been issued in Ukraine, which provides the following information on visual perception. Ministry of Regional Development, Construction and Housing and Communal Services of Ukraine (2018): "8.6.6. When forming excursion zones, it is necessary to consider that the object of tourism includes the territory itself and the zone of its comfortable visual perception. Dimensions of the zone of comfort perception must be determined by the radii: within the two heights of the object - for a separate memorial; up to $1.2 \mathrm{~km}$ for a complex of memorials, up to $2.5 \mathrm{~km}$ for urban ensembles, up to $5 \mathrm{~km}$ for significant natural objects.

Thus, we can define the main directions of studies on improvement of highways:

- influence of content and quality of roadside information on behavior;

- taking into account data of ecological psychology and human factor;

- emotional stress of driver when combining elements of the road;

- functional-planning and compositional-spatial organization of roadside landscapes;

- architectural and artistic solution of highways;

- estimation of aggressiveness of visual zones;

- estimation of information volume;

- determination of size and color of roadside constructions taking into account road conditions;

- visual reaction of the driver;

- quantitative assessment of theroad architectural solutionquality;

- causes of road traffic accidents;

- requirements for road signs and posters on roadside strip. 
Consequently, scientists from different countries of the world in their works devote considerable attention to the improvement of highways and determine its impact on road safety. It is necessary to take into account the essential inheritance of the work done in this direction, but there is need to improve existing researches, generalize them and define the principles of integrated placement of elements for the improvement of highways at the present stage of scientific thought development.

\section{Elements of identification and its classification}

Previously, the authors carried out a survey of Indian highways (Vinodhini and Sundram, 2016) and Ukraine (Lytvynenko et al., 2017) and identified the main elements of improvement (Fig. 6), which include identification elements (Fig. 7).

Improvement of highways is divided into such wide group of elements: artificial structures (bridges, overpasses, ramps, tunnels, pedestrian crossings, pipes, interconnections, retaining walls); elements of road traffic organization

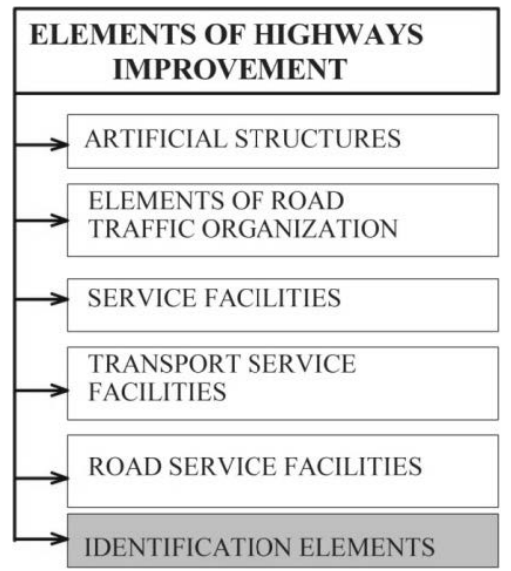

Fig. 6 Classification of elements for highways improvement

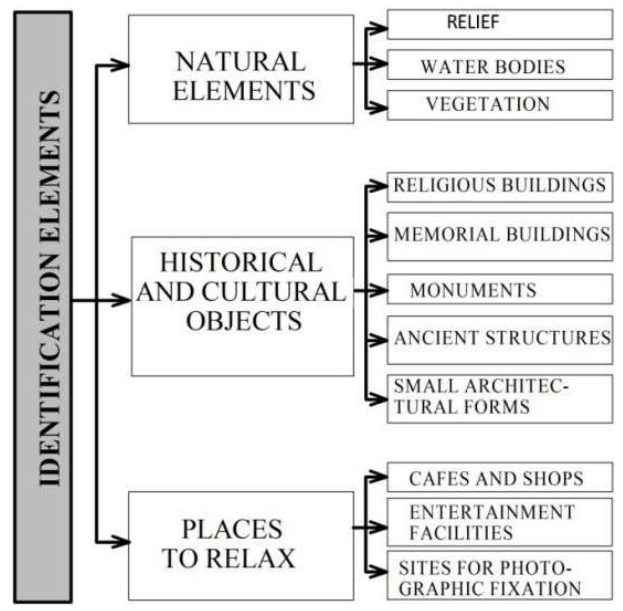

Fig. 7 Classification of identification elements (traffic signs, information boards, road markings, guiding devices, fences, lighting, telephones, drainage elements); service facilities (recreation sites, filling stations, canteens (cafe), items of trade (shops), rest homes, parking lots); transport service facilities (pavilions, landing places, stops, cargo and passenger bus stations); road service facilities (post assistance to victims of road accidents, building of communications, service points, production facilities, housing for workers, road service units, buildings of road management structures) and identification elements. From the observation of sites along tourist routes in India and Ukraine, it can be concluded that identification elements are largely attracting tourists along the road corridors that connect cities, settlements and villages in historically and culturally rich countries. Authors identify natural elements, historical and cultural objects and places to relax.

Natural objects (relief, water bodies, vegetation) attract attention by their picturesque character (Figs. 8, 9). These places are easy to determine because they stay in place for centuries or decades. They cause in the imagination of people associations and remain in their memory for a long time.

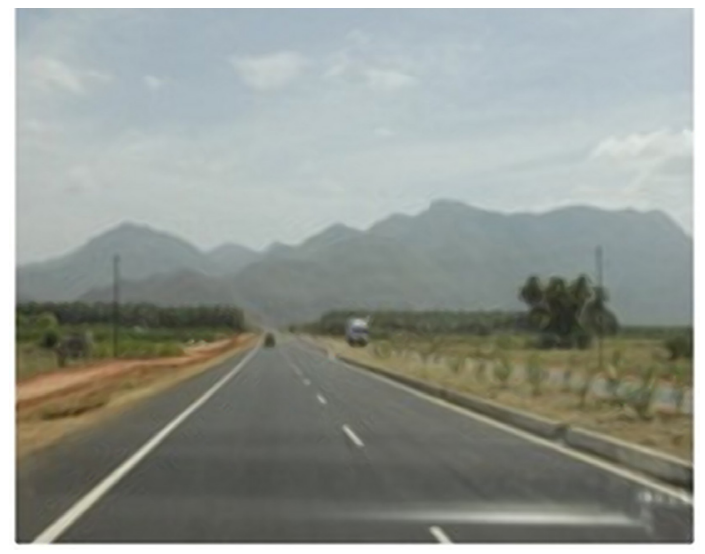

Fig. 8 The road to the city Madurai, India

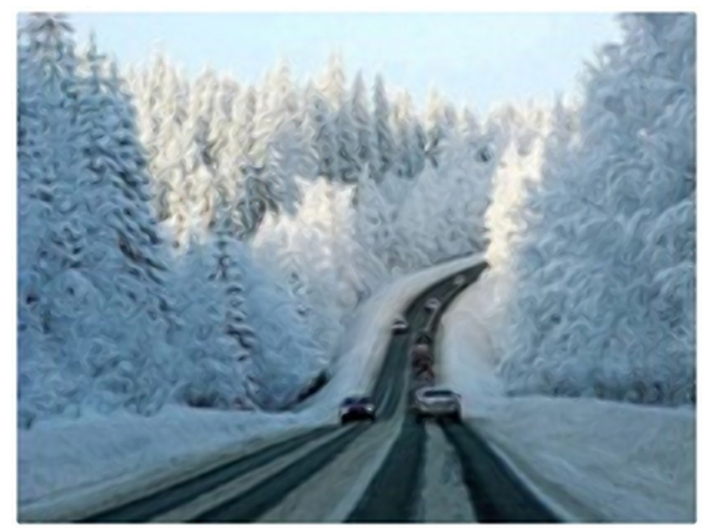

Fig. 9 The route Svaliava - Stryi, Ukraine 
Historical and cultural objects are the most important elements of identification. Every such object on the route of travel - a new discovery for the traveler, sometimes even the purpose of the trip (Petersenvet al., 2002). Often, religious buildings (temples, churches, shrines, etc.), memorial buildings, monuments, ancient buildings and structures or their remains, small architectural forms (Figs. 10, 11) are found among historical and cultural objects along the highways.

For many years, people have been looking for places to relax along travel routes (Tkachenko, 2013). Rest stones along hiking trails are now found in many villages. Routes with attractive cafes and shops (Fig. 12), entertainment facilities, sites for photographic fixation of buildings and landscapes (Fig. 13) attract more tourists than routes without such places of recreation.

\section{The basic properties of road space}

Modern psychology has proved the existence of a direct relationship between the mental state of man and the visual perception of the environment. Being in a monotonous visual environment, a person feels discomfort, she does not

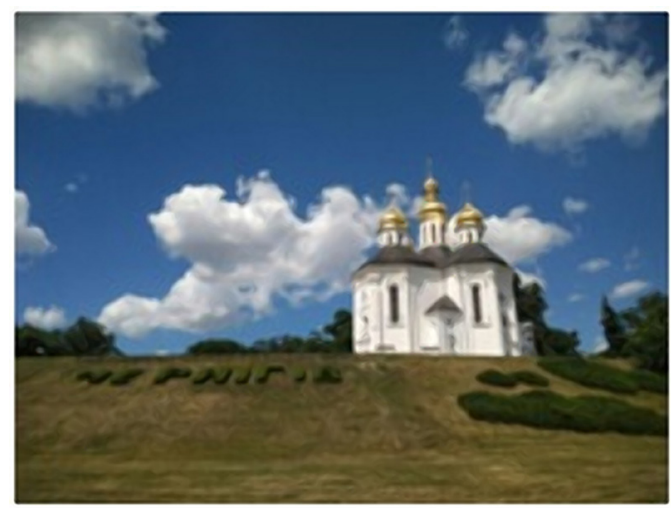

Fig. 10 The landscape, which opens immediately at the entrance to the city Chernihiv, Ukraine

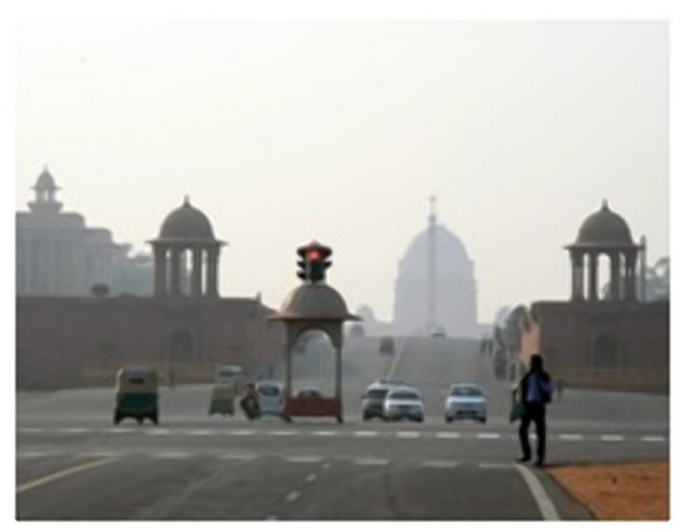

Fig. 11 The road to the memorial "Gate of India"

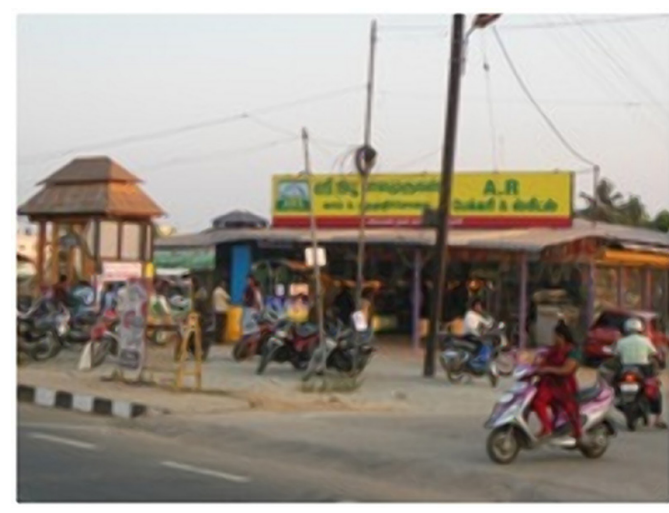

Fig. 12 Zone of rest along Indian road

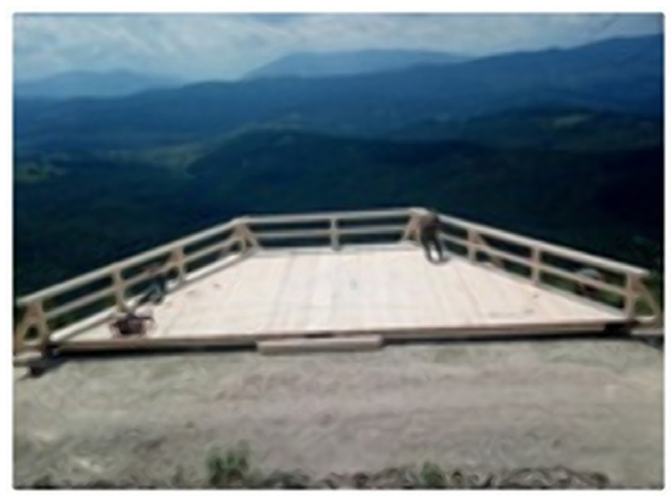

Fig. 13 A viewing platform near the road in the Carpathians, Ukraine

receive information and millions of identical pulses coming from the eyes lead the brain into a non-working state. Vision information can suppress the activity of many sensory systems. This is especially true in the perception of the road environment and is associated with both aesthetic requirements and traffic safety.

By acting through the means of visual information, the objects of road improvement directly contact with the person; because of the social, cultural, psychological impact on travelers, they form a social consciousness, enrich life (Boarnet, 2014).Due to the constant increasing of the road beautification means number, the issue of their perception by drivers and passengers becomes especially relevant, which creates the need to determine the location, size and aesthetic qualities (geometric dimensions, color).

So, are identified the following factors influencing on the visual perception of the road environment: speed, perception time, horizontal angle of view, vertical angle of view, distance of perception, level of eyes, weather conditions, relief, time of day, others (Fig. 14).

The perception of information, in the first place, depends on the peculiarities of the system of human vision, the main characteristics of which are horizontal (Fig. 15a) and vertical angles of vision (Fig. 15b): $\alpha 1, \alpha 2, \alpha 3, \beta 1, \beta 2$. These 


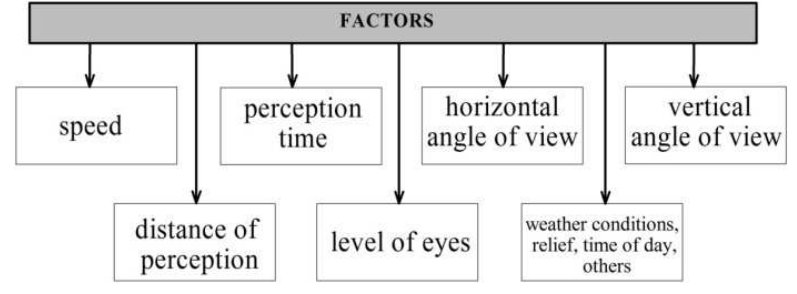

Fig. 14 Factors influencing the perception of the road environment by subjects of motion

a)

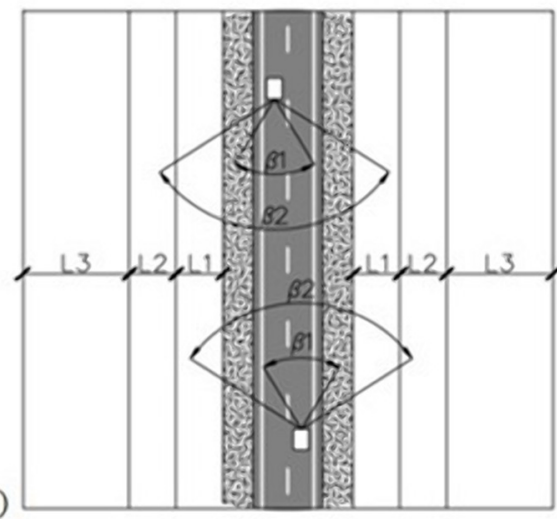

b)

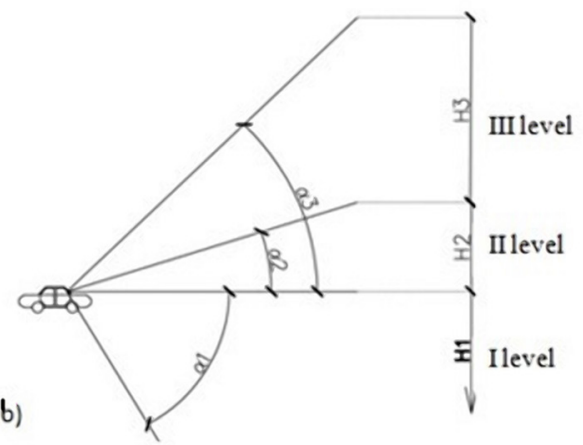

Fig. 15 Parameters of visual information perception: a) - horizontal spectrum; b) - vertical spectrum

angles limit the space that we can cover with one glance at a fixed position of the head. The clarity of perception of objects that are within this field of vision is different.

There are historical trails and historic settlements with prominent objects that can be taken over long distances if they are uncovered from an architectural point of view.

It is necessary to take into account local artistic traditions in the formation of road and roadside space, as well as the specifics of highways, consisting of the following features:

- irregular distances between different towns;

- different seasonal variations of climatic conditions (Fig. 16);

- economic underdevelopment and environmental vulnerability of some roadside areas (Fig. 17);

- chaotic landscaping that is not looked after (Fig. 18);

- insufficient capacity of existing highways (Fig. 19).

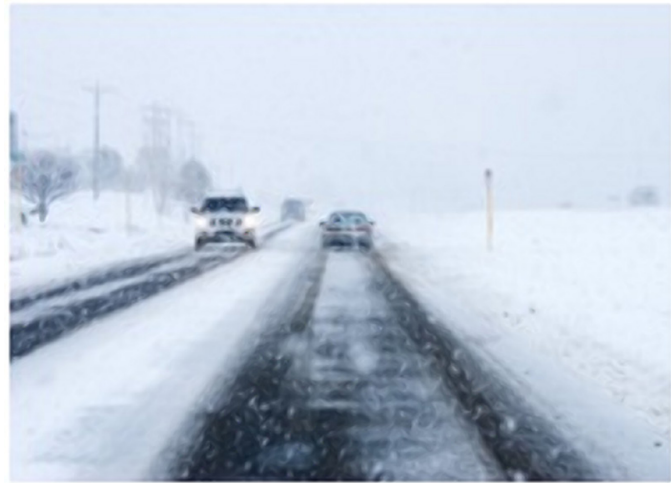

Fig. 16 The complexity of the visual perception of the Kiev-Kharkivroute (Ukraine) in winter conditions

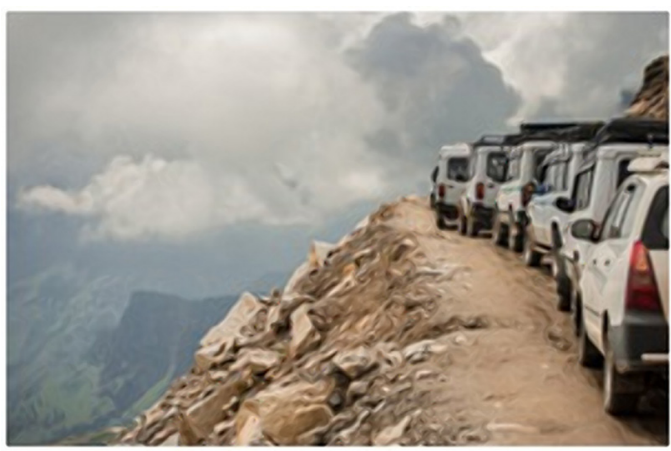

Fig. 17 Ecological vulnerability of the roadside area in the north of India

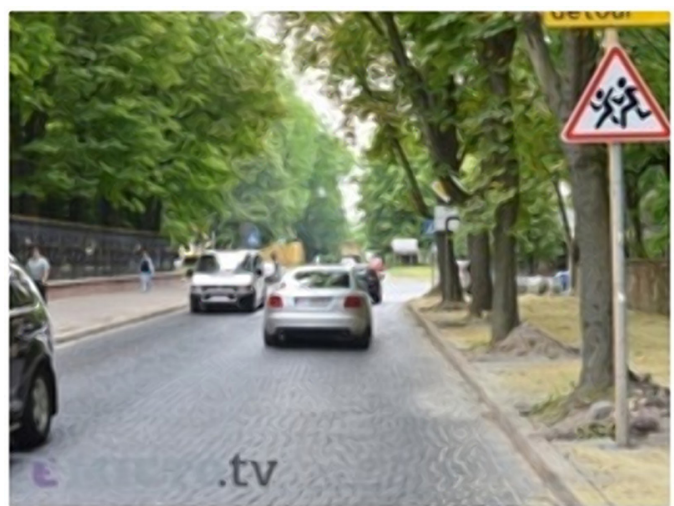

Fig. 18 The trunks of trees close road signs, Lviv, Ukraine

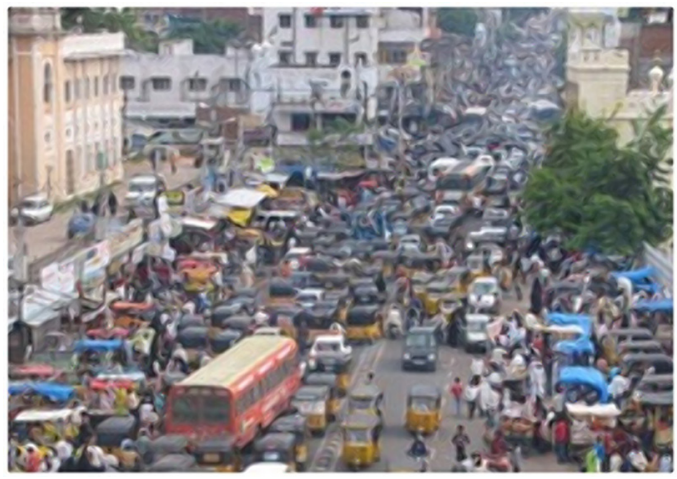

Fig. 19 Insufficient capacity of the Indian highway 


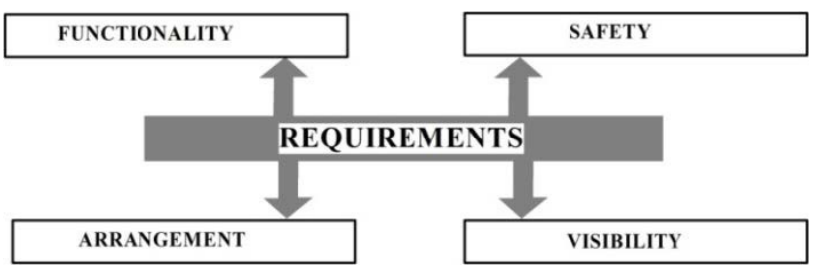

Fig. 20 Requirements for road space

The conducted research allowed formulating of the basic requirements for road space (Fig. 20):

- functionality (the ability to provide communication between territories);

- safety as physical as well as psychological;

- arrangement (availability of services and elements that provide both physical comfort and aesthetic qualities of the environment);

- visibility, is the possibility of observation, which presupposes the presence of natural and artificial prospects that identify the given area, taking into account elements of landscape, architectural and historical heritage, monuments, ensembles including religious appointment.

Properties of road space (Fig. 21, 22) can be formulated and described basing on sensory perception and emotional level using its following characteristics.

1. The main types of spatial situations.

These are the binary notions: exterior - interior, closed - open, geometric and regular - picturesque and irregular, integral-divided, horizontal - vertical.

2. Types of spaces on the basis of different sizes:

- personal human space (1.5-2 m). In roadside space it is sidewalks, cycle tracks, exits, entrances;

- collective space: chamber $(25-30 \mathrm{~m})$ and maximum enlargement (100-300 m). These are recreation areas, shopping malls, catering establishments, facilities for meals, rest etc.;

- the space of visibility of the object on the horizon (3000 m);

- total space of the highway (from $200 \mathrm{~m}$ and $>3000 \mathrm{~m}$ ).

The main feature is that linear continuous road spaces are perceived as a consistent overlay of a number of paintings that arise when moving along the active axis.

In the organization of the architectural environment of the road space the main role is played by the rhythmic construction of the spatial-temporal structure in the direction of motion, which is due to the functional process. Spatial rhythms are mainly related to functional requirements (transplantation, rest, food intake, etc.), in some cases, with features of relief, the presence of visually

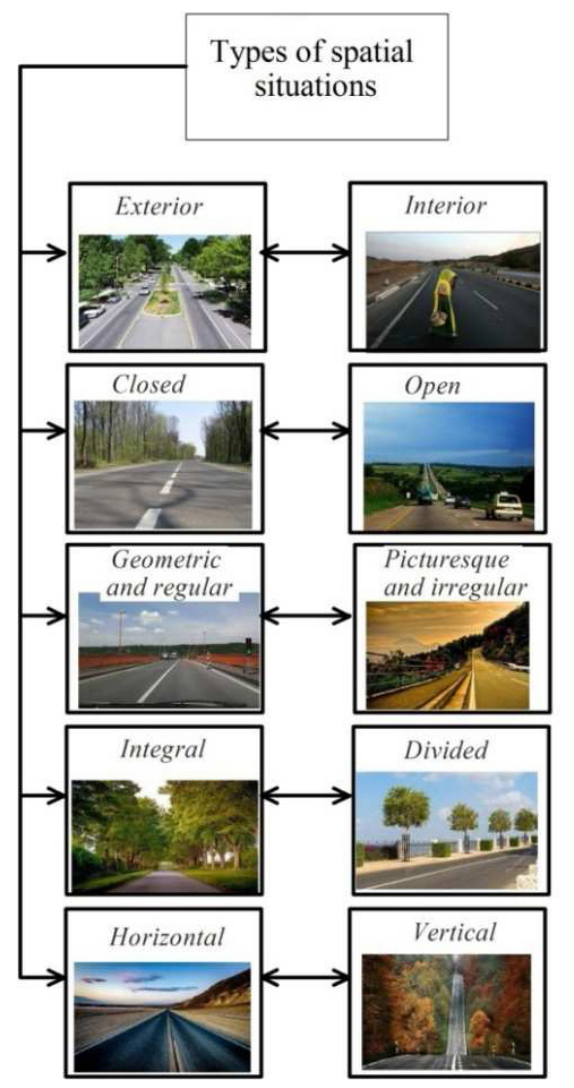

Fig. 21 The main properties of the road space for perception (spatial situations)

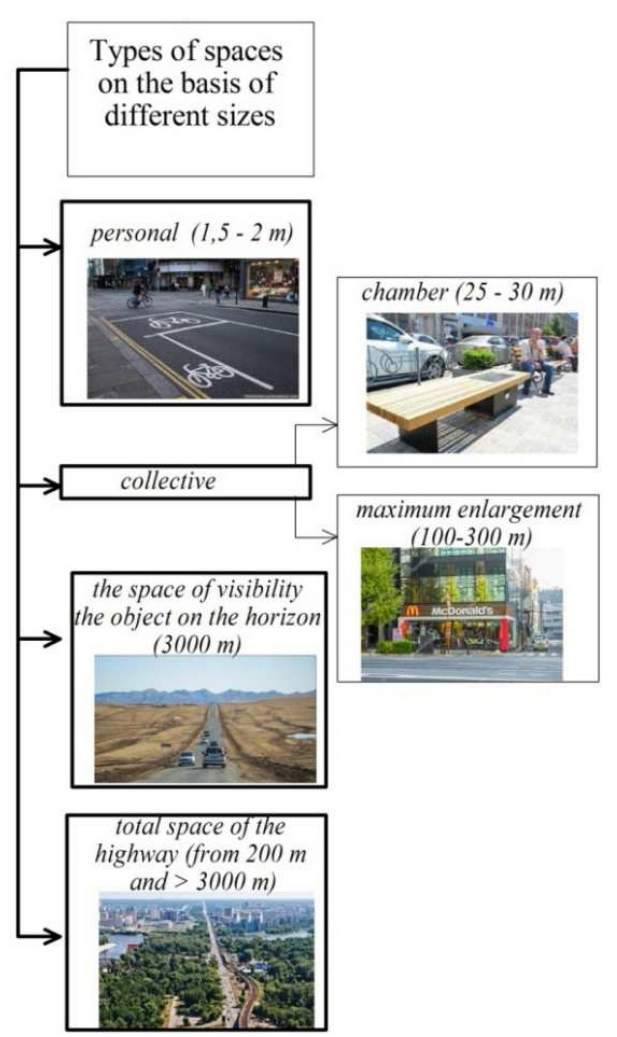

Fig. 22 The main properties of the road space for perception (spatial situations) 
active places and places of panoramic review, the properties of the landscape, as well as in connection with the socio-cultural and historical significance of existing sites of attractiveness for the population: monuments of history, culture, architecture and archeology, which must necessarily be taken into account for ancient historical territories with a high density of the road system in settlements.

In designing and reconstructing the road environment, great importance for perception have landmarks (Fig. 23). These are memorable forms - the dominant ones that form and can individualize the road environment. Landmarks are point elements that remain external to the viewer.

The leading principle of architectural and aesthetic organization of road and roadside space is the discovery and improvement of its architectural and landscape structure. It should take into account the following conditions that determine the limits and clarity of the review:

- nature and speed of the route (possibility of stopping from time to time, different upper and lower thresholds of speed, etc.);

- the state of the atmosphere in different periods of time in a complex of climatic and sanitary conditions (morning - day, twilight - night, good visibility - bad: fog, smog, dust, place of sun on the sky);

- possible angles of the landscape viewing (conditions of relief, straightness of the route, availability of buildings, historical monuments, cultural, archeology objects).

The aesthetic perception of the landscape largely shapes the general perception of the territory and has a great socio-political, cultural and historical significance, which is decisive in identifying the road network.

The next task of this work is quantitative calculation the basic functional requirements and determination the periodicity of the arrangement of stops in the road space.
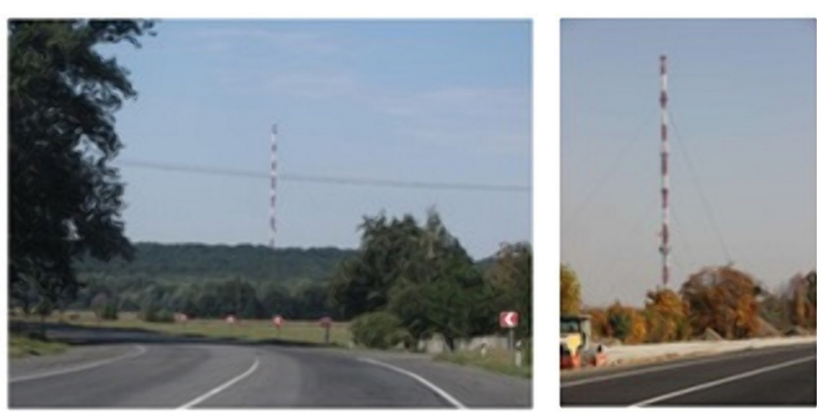

Fig. 23 Landmark - TV Tower at the entrance to Krasnogorovka village, Ukraine

\section{Placing of identification elements groups}

Logic and consistency in the development of architectural images is the main means of coordinating impressions on the road, a means of linking them into a figurative story about the terrain and nature of the area. It is necessary to identify the means of road architecture dominant and background as a means of architectural organization of space.

The road always leads a person to some purpose, and the dynamics of road constructions forms in space should become obvious for traveling people - the dynamics of the forms rhythm, directed to the main points of the road. As a rule, such goals of the movement are cities, and approaching them should be felt from afar. This can be achieved as a result of the clearly expressed rhythm of all forms visible on the road - as the consistent dynamics of two or three architectural pools in front of the city, and the dynamics within each of them, and especially in the last pool in front of the city. The same must be clearly expressed dynamics, directed toward large bridges, in the mountains - in the direction of the passes, as natural boundaries. This development of the "brightness" of architectural solutions along the length of the highway was illustrated by Ornatskij (1986) (Fig. 24).

"Brightness" of accents increases with approaching to composite centers, which is represented by the height of conditional columns - dominant. At the same time, each dominant itself is a composite axis or the center of its architectural pool - even when it is located on the edge of the pool, separating them among themselves.

A special place in the architecture of the road is occupied by large settlements, through which or bypass is laid road, large bridge crossings, end points of roads. Depending on the length and expressiveness of their accomplishment, they can form an independent architectural pool or serve as dominant and center of pool compositions.

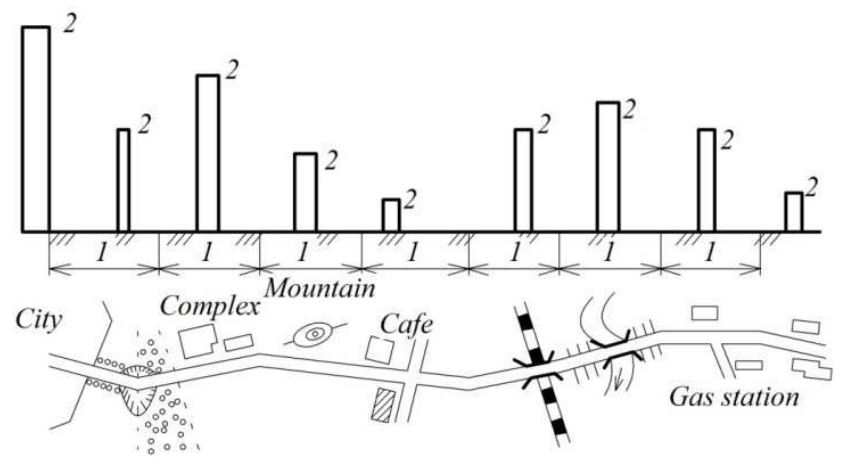

Fig. 24 Scheme of architectural composition of highways: 1 - architectural pool; 2 - dominant 
Within the landscape of one pool, there is a homogeneous background and accents that stand out against this background and attract attention. The assignment of one and the same element of the landscape to the background or to accent depends mainly on how often this element is repeated and how sharply it differs from neighboring elements similar to it. Any element of unusual shape, color or size does not strike by itself - it should be underlined, highlighted (accented) by other elements.

There are two types of accents on the road. In one case, they divide the architectural pools with each other, being on the edge of the pool, and in the rest they can be dominant, sharply stand out (dominant) on a generally homogeneous background inside the pool. Only the ratio of the road landscape elements, which is noticeable from afar (at a distance of optimal visibility), can be dominant and may be the center or the main axis of the architectural composition of the pool.

Functions of visual accents can be realized by various elements of improvement. The most significant elements of the road must be in the compositional center of the opening view, in advance to attract driver's view on the entire length of the adjacent landscaped pool.

The boundaries of the architectural pool should coincide with the most prominent convex fractures of the longitudinal profile, so that a large part of the pool can be seen from its elevated edges. Borders of architectural pools can be not only noticeable vertical curves, but also settlements, borders of landscapes, characteristic turns in the plan, combined with a landmark, which is allocated by sight (accent).

A peculiar combination of monumental design and road signs are route schemes and signposts of cities, which are most often dominant at the boundaries of architectural pools or elements emphasizing dominant.

Each architectural pool as a part of the whole ensemble will be remembered only if it is different from the neighbor, if the driver or the passenger will have time to notice this difference and to realize it, if the architectural design does not seem to be exhausting due to its excessive length. Depending on the type of influence of various factors, the time of movement within a single pool can be tolerated within 3-5 minutes.

The survey of the best roads in Ukraine showed (Tkachenko, 2013) that look well the pools with a length of 4-8 km and with their length less than $3 \mathrm{~km}$ the road is no longer perceived as an independent segment of the road, becoming part of a longer section.
From engineering psychology it is known that the time of the perception of a new signal (the reaction time in a new environment) can reach $3 \mathrm{~s}$, and after $4 \mathrm{~s}$ of observation spectators begin to show signs of impatience. Let's take the average length of the perception cycle equal to $3.5 \mathrm{~s}$ and we will assume that the perception of any gaps in the plantations, in the building should last no more than 3.5 seconds. Then the boundary (estimated) length of the discontinuities (in $\mathrm{m}$ ) will be numerically equal to the speed (in $\mathrm{km} / \mathrm{h}$ ) $l_{p}=V_{p}$.

For a quiet contemplation of picturesque places from the road at the estimated speed of $100 \mathrm{~km} / \mathrm{h}$ the estimated length of the gaplp $=100 \mathrm{~m}$ is required, and the project takes more, for example 120-150 m (Fig. 25a). On the contrary, wishing to decorate, hide something, for example a roadside quarry, and at this time to preserve the entrances to this object, it is necessary to set the length of the gap less than the limit, in this case $60 \mathrm{~m}$ (Fig. 25b).

A structural spatial corridor model of a road was constructed and divided into four subcorridors to deploy beautification elements in accordance to the level of importance. Spatial corridor and subcorridors were described by the following characteristics. There are $B_{c o r}, H_{c o r}, L_{c o r}$ - width, height and length of spatial corridor in accordance; $B_{1}, D_{1} ; B_{2}, D_{2} ; B_{3}, D_{3} ; B_{4}, D_{4}$ - width and length of spatial subcorridors in accordance. The next step of work was dedicated to deducing of the equations. for calculating the parameters of spatial corridors and subcorridors.

The width of spatial corridor. The minimum width of the road spatial corridor and width of spatial subcorridors of different importance level for optimal human perception the author proposes to define by the Eqs. (1)-(5):

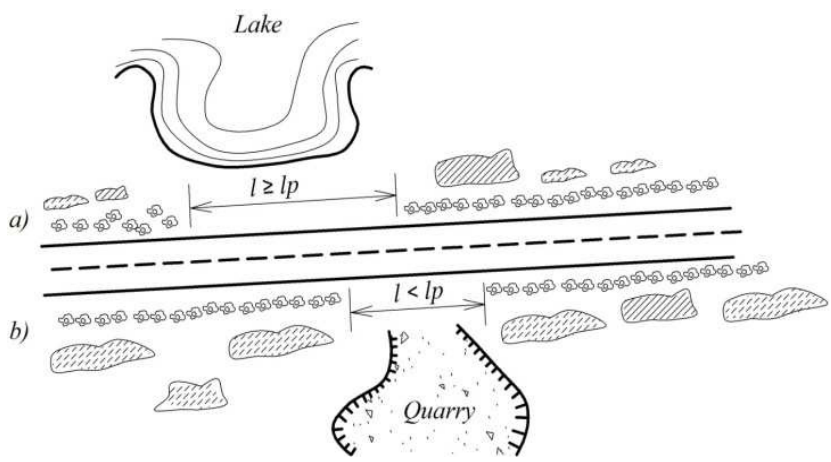

Fig. 25 Examples of determining the length of the gap in plantations along the road: a) - in order to reveal the species on the landscape (the length of the gap is more than the limit); b) - for the purpose of decoration (the length of the gap is less than the limit) 
set of pausepoints,

$B_{3}=$ The lane next to $B_{2}$ with second set of pausepoints well recessed from the right of way $B_{1}$,

$B_{4}=$ The lane adjacent to $B_{3}$ with more permanent pausepoints with built structures,

$B_{c o r}=B_{1}+2\left(B_{2}+B_{3}+B_{4}\right)$,

where $B_{1}, B_{2}, B_{3}, B_{4}$ - the width of first, second, third and fourth spatial subcorridors in accordance; $B_{c o r}$ - the width of road and street spatial corridor; $B_{1}$ is the road where vehicular movement if found, especially traveling at higher mean speed along highways; $B_{2}$ has more natural elements which are predominantly trees and temporary structures; $B_{3}$ has semi-permanent structures which are well recessed and hence provide ample parking space; $B_{4}$ has permanent built structures which accommodate pause points with longer duration of rest. A typical stretch along a highway with elements marked for discussion showcases the spatial location of present elements as shown in Fig. 26.

The location of these elements can be predicted by the following calculations: The placing of elements shall also be designed based on the distance interval between two elements, based on biological rest points and the time taken to reach that distance. The identity element location equations can be predicted with the following methods.

Location of pause points can be placed considering the different age groups and starting points of travel and this subjectively depends on the person traveling and their physical condition and ailments. Equations to calculate the distance between two consecutive pause points are as per the following predictive calculations.

\subsection{Based on biological rest limit}

Human body requires rest at minimum of 3 to 4 hours. As per the subjective survey, it is observed that generally people pause at 2 to 3 stops along their travel routes such as $(1 / 2 \times t)$ or two-thirds the time of travel $(2 / 3 \times t)$. Based on these results of number of stops along a highway during travel is considered. The distance of pause points can be calculated as shown in Eqs. (6) and (7).

Where stopping time is $1 / 2$ of travel:

$$
D P b_{1}=\frac{1}{2} T \cdot S_{\text {avg }} \text {. }
$$

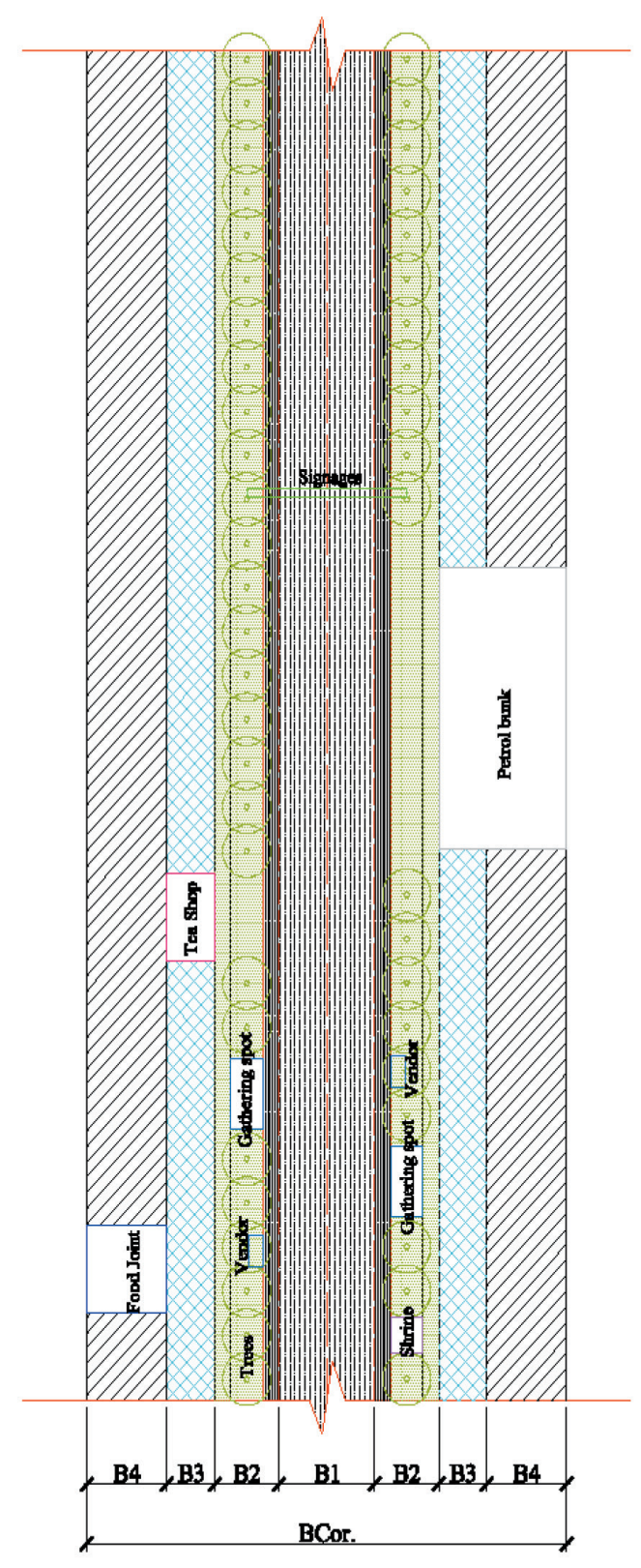

Fig. 26 A typical spatial corridor along the highway

Where stopping time is two-thirds of travel:

$$
D P b_{2}=\frac{2}{3} T \cdot S_{a v g} .
$$

Where $D P b_{1}$ and $D P b_{2}$ are the distances between pause points, $T$ is the total duration of traveling time between the two nearest urban areas or points of travel and $S_{\text {avg }}$ is the average speed of travel.

For example, in a traveling distance of $300 \mathrm{kms}$, it is found in the subjective survey that people either stop midway at $150 \mathrm{kms}$ or two-thirds the distance at $100 \mathrm{kms}$ in the Indian context with the average mean speed permitted at $100 \mathrm{~km} /$ hour and $80 \mathrm{~km} /$ hour on different roads. 


\subsection{Based on distance from the nearby urban area}

The distance between pause points can be calculated as shown in Eq. (8):

$$
D P_{u}=\frac{L_{T}}{N_{S}+1} .
$$

Where $D P_{u}$ is the distance between pausepoints, $L_{T}$ is the total length between the two nearest urban areas or points of travel and $N_{S}$ is the number of stops required as per the need of the travelers.

\subsection{Based on distance from the nearest landscape} characteristic element such as rock, hills, water body, etc The distance of pause points can be calculated as shown in Eq. (9):

$$
D P_{c}=\frac{L_{T}}{N_{c e}+1} .
$$

Where $D P_{c}$ is the distance between pausepoints, and $N_{c e}$ is the number of stops required as per the position of the landscape characteristic element.

\section{References}

Boarnet, M. G. (2014) "National transportation planning: Lessons from the U.S. Interstate Highways", Transport Policy, 31, pp. 73-82. https://doi.org/10.1016/j.tranpol.2013.11.003

Florek, J. (2010) "On Barnette's conjecture", Discrete Mathematics, 310(10-11), pp. 1531-1535. https://doi.org/10.1016/j.disc.2010.01.018

Kobernik, S., Kovalenko, R. (2017) "Географія. Підручник. 9 клас" (Textbook Geography. Grade 9), Abetka Publishing House, Kamianets-Podilskyi, Ukraine. (in Ukrainian)

Lytvynenko, T., Tkachenko, I., Gasenko, L. (2017) "Principles of the Road Beautification Elements Placing", Periodica Polytechnica Transportation Engineering, 45(2), pp. 94-100. https://doi.org/10.3311/PPtr.8592

Ministry of Regional Development, Construction and Housing and Communal Services of Ukraine (2018) "ДБН Б.2.2-12:2018 Планування i забудова територій" (DBN B.2.2-12:2018 Planning and building of territories), Kyiv, Ukraine. (in Ukrainian)

Morgan, B. (2010) "The Hill", Ecotone, 5(2), pp. 129-141. https://doi.org/10.1353/ect.2010.0059

Nagendra, H., Gopal, D. (2010) "Street trees in Bangalore: Density, diversity, composition and distribution", Urban Forestry \& Urban Greening, 9(2), pp. 129-137. https://doi.org/10.1016/j.ufug.2009.12.005

Ornatskij, N. P. (1986) "Благоустройство автомобильных дорог" (Improvement of highways), Transport, Moscow, Russia. (in Russian)

\section{Conclusions}

1. It has been determined that the road network should be considered as a holistic linear architectural environment in unity with the natural environment in accordance with the level of development, technical progress, economy and culture. For this purpose, it is necessary to combine various-scale and diverse objects of the architectural environment and natural elements into a coherent system.

2. This communication space should be comfortable for all categories of participants (drivers, passengers). In addition to solving purely utilitarian tasks, it is necessary to reveal the city-planning and historical and cultural potential of this environment.

3. Carried out by the authors studies of literary sources and road corridors of Ukraine and India allowed to perform the classification of identification elements, identify factors that influence the visual perception of the road environment, formulate specific features of the road space and the basic requirements for it.

4. Having examined the main properties of the road space, the authors considered the features of the placement of identification elements and proposed principles for calculating distances between stopping points along highways.

Peterson, M. N., Peterson, T. R., Peterson, M. J., Lopez, R. R., Silvy, N. J. (2002) "Cultural Conflict and the Endangered Florida Key Deer", The Journal of Wildlife Management, 66(4), pp.947-968. https://doi.org/10.2307/3802928

Scannell, L., Gifford, R. (2010) "Defining Place Attachment: A Tripartite Organizing Framework", Journal of Environmental Psychology, 30(1), pp. 1-10. https://doi.org/10.1016/j.jenvp.2009.09.006

Tkachenko, I. V. (2013) "Принципи розміщення елементів благоустрою автомобільних доріг" (Principles of accommodation of elements for the improvement of highways), PhD Thesis, National Aviation University. (in Ukrainian) [online] Available at: https://mydisser.com/dfiles/02762202.doc [Accessed: 11 October 2018]

Vinodhini, O., Sundaram, A. M. (2015) "Issues in Indian Cities Due to Increasing Coverage of Highways: A Case Study of The Sriperumpudur - Poonamalle Stretch in NH4", Creative Space, 2(2), pp. 197-212. https://doi.org/10.15415/cs.2015.22010

Vinodhini, O., Sundaram, M. (2016) "Landscape Elements of Highways in TamilNadu, India: A comparison between the old and the new (Case Study of a Stretchin NH 67- Manaparaito Coimbatore, TamilNadu, India)", In: Proceedings of Asian Studies, Unique Conferences, Toronto, Canada, pp. 137-144. 